\title{
Antimicrobials for food and feed; a bacteriocin perspective
}

Paula M. O' Connor ${ }^{1,2^{*}}$, Taís M. Kuniyoshi ${ }^{1,3^{*}}$, Ricardo P. S. Oliveira ${ }^{3}$, Colin Hill ${ }^{2,4}$ and R. Paul Ross ${ }^{2,4}$, Paul D. Cotter ${ }^{1,2^{* *}}$

${ }^{1}$ Teagasc Food Research Centre, Moorepark, Fermoy, Co. Cork, Ireland.

${ }^{2}$ APC Microbiome Ireland, University College Cork, Ireland.

${ }^{3}$ Biochemical and Pharmaceutical Technology Department, Faculty of

Pharmaceutical Sciences, University of São Paulo, Av. Lineu Prestes 580, São

Paulo 05508-900, Brazil

${ }^{4}$ School of Microbiology, University College Cork, Ireland.

* These authors contributed equally to the manuscript

${ }^{\star *}$ Corresponding author:

Paul Cotter,

Teagasc Food Research Centre, Moorepark, Fermoy, Co. Cork, P61 C996, Ireland.

Email: paul.cotter@teagasc.ie

Tel: $+353(0) 2542694$ 


\section{ABSTRACT}

Bacteriocins are natural antimicrobials that have been consumed via fermented foods for millennia and have been the focus of renewed efforts to identify novel bacteriocins, and their producing microorganisms, for use as food biopreservatives and other applications. Bioengineering bacteriocins or combining bacteriocins with multiple modes of action (hurdle approach) can enhance their preservative effect and reduces the incidence of antimicrobial resistance. In addition to their role as food biopreservatives, bacteriocins are gaining credibility as health modulators, due to their ability to regulate the gut microbiota, which is strongly associated with human wellbeing. Indeed the strengthening link between the gut microbiota and obesity make bacteriocins ideal alternatives to Antibiotic Growth Promoters (AGP) in animal feed also. Here we review recent advances in bacteriocin research that will contribute to the development of functional foods and feeds as a consequence of roles in food biopreservation and human/animal health.

\section{INTRODUCTION}

Fermented foods have been part of the human diet for thousands of years and evolved through the need to extend shelf life and improve food safety via the inhibition of food spoilage/pathogenic micro-organisms ${ }^{1,2}$. Lactic acid bacteria (LAB) are natural constituents of many fermented foods and contribute greatly to food biopreservation. LAB exert their preservative effects through the production of antimicrobial metabolites including organic acids, diacetyl, ethanol, hydrogen peroxide and bacteriocins. Bacteriocins are a heterogeneous group of ribosomallysynthesised antimicrobial peptides with the ability to kill closely related (narrow spectrum), or a diverse range of (broad spectrum), microorganisms ${ }^{3}$. Bacteriocins are frequently very potent, being active at nanomolar concentrations, and exert their killing effect predominantly through membrane permeabilization. They are broadly divided into two classes with Class I containing Ribosomally synthesised and Post translationally modified Peptides (RiPPs) and Class II containing predominantly unmodified peptides ${ }^{4}$. Bacteriocins are produced by generally regarded as safe (GRAS) or qualitative presumption of safety (QPS) organisms and are generally sensitive to human proteases. Bacteriocins are now the focus of increased attention 
due to i) consumer requirements for minimally processed foods free from chemical additives $^{5}$ ii) their potential as natural alternatives to antibiotics due to increasing concerns about the emerging problem of antimicrobial resistance ${ }^{4,6}$ iii) as modulators of the human microbiome and, therefore, potential to address complex metabolic conditions such as diabetes and inflammatory bowel disease ${ }^{7}$ and iv) as bacteriocin producing probiotic cultures for inclusion in animal feed to promote growth, improve animal health and/or reduce infection ${ }^{8}$ (Figure 1).

\section{BACTERIOCINS AS FOOD BIOPRESERVATIVES}

Bacteriocins with optimal potential as biopreservatives are safe for human consumption, have minimal effects on the human microbiota, are effective against food pathogens/spoilage micro-organisms and stable in the food matrix in which they are employed, which may require resistance to heat, $\mathrm{pH}$ and food associated enzymes $^{9}$. Bacteriocins can be added to foods in three ways; i) as a pure bacteriocin preparation ii) as bacteriocin containing fermentates or iii) as bacteriocin producing cultures ${ }^{4}, 10$.

Nisin A is a broad spectrum Class I lantibiotic, produced by Lactococcus lactis, characterized by five intermolecular lanthionine rings that confer inherent heat and protease stability. It is the most studied bacteriocin and it is the only commercially produced bacteriocin approved as a food additive by regulatory agencies including the World Health Organisation (WHO)/Food Development Authority (FDA) in the USA and the European Food Safety Authority (ESFA) in Europe ${ }^{11}$. It was first produced in England in the 1950s ${ }^{1}$ and is now available as, for example, Nisaplin (2.5\% nisin) (www.dupontnutritionandsciences.com $)^{11}$. Nisin Z, a His27Asn variant of nisin $\mathrm{A}$, with greater solubility at higher $\mathrm{pH}$, thereby extending its usefulness for food applications, is also commercially available as, for example, Nisin $Z^{\circledR} \mathrm{P}$ ultrapure nisin (>95\% nisin) (www.handary.com). The ability to bioengineer nisin has led to a number of nisin variants with improved capabilities, perhaps the most notable of these being nisin V, a Met21 Val variant, which has improved activity against a variety of foodborne pathogens, including Listeria monocytogenes and Bacillus cereus $^{12}$. Nisin variants can be bioengineered through food grade techniques involving double crossover mutagenesis which do not introduce exogenous DNA or 
antibiotic resistance markers and, when made in this way, the producing strains are not regarded as genetically modified micro-organisms by the EFSA under contained use legislation. This opens the possibility to custom design nisin for specific applications by increasing yield, increasing potency against specific targets or expanding its spectrum of inhibition thereby increasing its commercial potential as a food biopreservative ${ }^{13}$.

Bacteriocin containing food-grade fermentates are also commercially available and widely used in the food industry. These include the FDA approved MicroGARD ${ }^{T M}$ range from Danisco and ALTA 2431 from Quest International and both contain pediocin PA-1 produced by Pediococcus acidilactici ${ }^{5}$.

Bacteriocin producing cultures used as starter cultures or as adjunct cultures serve a dual purpose as they can contribute to both flavour and food safety, providing fermentation and preservation simultaneously. This is more cost effective than using pure peptide and is subject to less regulatory control ${ }^{9}$. Examples include the Bactoferm $^{\mathrm{TM}}$ range (www.chr-hansen.com), containing pediocin and sakacin producing strains, used to make fermented sausages and dry cured meat and HOLDBAC ${ }^{\circledR}$ protective cultures (www.dupontnutritionandsciences.com) containing a mix of bacteriocin producing strains used to protect seafood, meat and dairy products from Listeria, yeasts and moulds ${ }^{9}$. Micocin ${ }^{\circledR}$ is a specifically designed protective culture with potent activity against food spoilage and pathogenic microorganisms in ready to eat meat products and approved for use in the US and Canada $^{14}$. It contains Carnobacterium maltoaromaticum which produces piscicolin 126 and carnobacterium BM1 and the circular bacteriocin, carnocyclin $A$, that is particularly potent against $L$. monocytogenes ${ }^{15}$. Including Micocin ${ }^{\circledR}$ as a feed additive in the diet of Grimaud rabbits resulted in reduced levels of $L$. monocytogenes in ground meat during storage indicating that including a protective culture in animal diets resulted in safer food products ${ }^{16}$.

Recently discovered novel bacteriocins with potential as food preservatives include plantaricyclin A, a circular bacteriocin produced by the olive isolate Lactobacillus plantarum NI326, with activity against the beverage spoilage bacterium Alicyclobacillus acidoterrestris, which causes significant economic losses to the industry every year ${ }^{17}$. Enterococcus mundtii CRL35, a non-virulent, non-antibiotic 
resistant strain, also shows promise as an adjunct culture. It reduces $L$. monocytogenes during meat fermentation, both in vitro and in a beaker sausage model in the presence of curing agents, due to production of enterocin CRL35, a class Ila bacteriocin. Bacteriocin producing strains are adversely affected by the presence of curing salts so the ability of $E$. mundtii to grow and exert a higher protective effect in fermented meats is particularly advantageous ${ }^{18}$. Gómez-Sala et al (2016) found that the use of the multi-bacteriocinogenic strain Lactobacillus curvatus BCS35 as a protective culture, and of its cell free supernatant used as a food ingredient during refrigerated storage, significantly reduced bacterial counts on fresh fish, thereby increasing the both the quality and commercial value of the product ${ }^{19}$. Another exciting development in recent years is the use of antimicrobial-containing edible films and coatings, composed of layers of biopolymers that protect the food from the environment, to improve food safety by inhibiting food pathogens during handling, transportation and storage of food products ${ }^{5,20}$.

\section{ANTIMICROBIAL RESISTANCE}

A recent WHO report highlights concerns about the lack of progress in the search for new antimicrobial classes and calls for increased investment in drug discovery to combat the threat of antimicrobial resistance ${ }^{6,21}$. Bacteriocins are considered promising alternatives due to their stability (especially in the case of modified peptides such as the lantibiotics), low toxicity, frequently excellent potency and potential for target specificity. Many bacteriocins interact electrostatically with the cell membrane and introduce permeabilisation through interaction with receptor or docking molecules. Resistance can occur due to innate mechanisms, including the ability to produce degradation enzymes or the presence of immunity proteins, while acquired resistance occurs due to horizontal gene transfer or gene mutations that alter the cell membrane, binding receptors or transport systems ${ }^{22,23}$. Previously described resistance mechanisms include specific adaptations such as the loss of a receptor, as seen in resistance to class lla bacteriocins like pediocin, or non-specific adaptations that alter the cell envelope as seen in the case of resistance to Class I lantibiotics such as nisin ${ }^{10,22,24,25}$. Radical adaptations requiring high energy costs that reduce the fitness of the cell, may limit the ability of resistant mutants to 
compete in established niches, possibly explaining why bacteriocin resistance is rarer than antibiotic resistance ${ }^{24,26,27}$. Knowledge of a bacteriocins mode of action ${ }^{4}$ and how it acquires resistance facilitates the development of methodologies to minimise resistance occurrence ${ }^{27}$. Strategies successfully used to reduce resistance include combining bacteriocins with other bacteriocins with different modes of action $^{23,28,29}$, other antimicrobials ${ }^{21,25}$, or phages or, generating peptides with increased antimicrobial resistance through bioengineering ${ }^{30}$. These hurdle (combinatorial) approaches have the added advantages of broadening the antimicrobial spectra while reducing costs and toxicity ${ }^{25}$. Indeed, Perales et al (2018) found that a combination of enterocin AS-48 and nisin A acted synergistically to kill antibiotic resistant staphylococci, a common contaminant in processed food, in fresh goat milk cheese, potentially improving its shelf life and safety. Using multiple bacteriocins reduces the bacteriocin dose and prevents the regrowth of bacteriocin resistant/adapted cells ${ }^{21}$. Mills et al (2017) also used a multi-bacteriocin approach to develop a cheese starter system producing both nisin A and lacticin 3147. The use of these, in combination with a Lactobacillus plantarum Class II plantaricin producer, reduced $L$ isteria numbers in lab scale cheese more effectively than when individual bacteriocin producers were used singly. The concurrent production of nisin $A$ and lacticin 3147 reduces the likelihood of incidence of bacteriocin resistance and this approach shows great potential for food safety applications ${ }^{31}$.

A bioengineering approach was used to overcome the efficacy of nisin resistance protein (NSR), expressed by some microorganisms, that cleaves nisin between residue 28 , involved in ring $E$ formation, and serine 29 resulting in a truncated nisin 1-28 with significantly reduced activity ${ }^{30}$. A screening study located a nisin Ser29Pro variant with 20 fold increased activity against a $\mathrm{NSR}^{+}$strain and a similarly resistant nisin PV variant that was less affected by oxidation ${ }^{30}$. Recently, a survey of 182 Lactobacillus strains revealed a high level of intrinsic antimicrobial resistance genes, with resistance to kanamycin, vancomycin and trimethoprim being most prevalent ${ }^{32}$. Eighty eight per cent of the strains surveyed would fail EFSA regulatory guidelines, despite them being species widely used in foods for human and animal consumption, as the presence of antimicrobial resistance genes impacts on their use in food applications. These findings led the authors to call for revision of EFSA regulatory guidelines for lactobacilli entering the food chain and highlight that a more thorough 
understanding of antimicrobial resistance and its spread within microorganisms is required $^{32}$. Overall, the general consensus is that bacteriocins, like antibiotics, should be used exiguously to avoid selection of resistant phenotypes that may compromise their potential role as biopreservatives ${ }^{22,24,25}$.

\section{BACTERIOCIN PRODUCING PROBIOTIC STRAINS AS GUT MICROBIOME MODULATORS}

The role of the gut microbiota in human health is of increasing interest as the links between a balanced, healthy gut microbiota and disease prevention become more apparent ${ }^{23,33}$. Broad spectrum antibiotics indiscriminately affect the entire microbiota, leading to imbalances that could potentially predispose to conditions such as obesity, diabetes, immune disorders and neurodegenerative disease ${ }^{29,34,35}$. Bacteriocinproducing $L A B$ are antibiotic alternatives that have the potential to enhance gut health through their ability to survive the gut environment, inhibit pathogens and competitors, modulate the immune system and prevent inflammation and oxidative stress $^{33,34,36,37}$. Considerable efforts are being made to understand the contribution of bacteriocins produced by LAB to gut modulation, pathogen inhibition and their role in the maintenance of host health. To this end, an in vitro faecal fermentation system that mimics the anaerobicity of the colon was used to assess the effect of bactofencin A, a class Ild bacteriocin, produced by the porcine gut isolate Lactobacillus salivarius, on the human faecal microbiota. The study found subtle but positive differences in taxonomic profiles between the bactofencin $\mathrm{A}^{+}$producing culture and its bactofencin $A^{-}$mutant, while more drastic effects in taxonomy were detected in the presence of pure peptide ${ }^{38}$. Similarly, in vivo studies using mice fed with a $L$. salivarius UCC118 bacteriocin producer, $\mathrm{Bac}^{+}$, or its bacteriocin-negative, $\mathrm{Bac}^{-}$, derivative over 8 weeks resulted in slight changes in the gut microbiota at the Phylum level whereas at the genus level, the $\mathrm{Bac}^{+}$treatment resulted in a significant increase in Bacteroides spp. and decrease in Bifidobacterium spp. in comparison with the $\mathrm{Bac}^{-}$group ${ }^{39}$. Efforts to assess if bacteriocin production in vivo inhibits gut pathogens without negatively impacting beneficial populations require rigorous experimental methods to provide meaningful results ${ }^{40}$. Bauer et al (2017) describe a generic method, using compositional 16S rDNA combined with bioinformatics, to 
compare the effect of bacteriocin producers to their isogenic non-producing equivalents on microbiota composition in a mouse model allowing impacts on the gut microbiota to be measured in a live animal model ${ }^{36}$. This model was used in a mouse feeding trial, where five Class II bacteriocin-producing LAB were compared with isogenic non-producing equivalents, and showed that while the overall diversity was unchanged, advantageous changes relating to pathogen inhibition and increased LAB levels were seen briefly, suggesting that bacteriocin production facilitated favourable changes without collateral damage to the gut microbiota ${ }^{41}$. These studies provide further evidence that bacteriocin production provides subtle positive changes at lower taxonomic levels that maintain a desirable gut microbiota and are beneficial to the host ${ }^{7}$.

Bacteriocins, unlike antibiotics, are often very specific and can kill pathogens without causing detrimental imbalances to the host microbiota. Vancomycin resistant enterococci (VRE) are gut inhabitants that can cause fatal infections, particularly in a hospital environment. A recent report by Kim et al (2019) describes the ability of gut commensals to increase the resistance of the host to vancomycin resistant Enterococcus faecium (VREf). They found that one constituent of a four strain cocktail, Blautia producta BPscsk, a nisin A variant producer, was responsible for reduced colonisation by VRE and a direct correlation was found between the amount of the lantibiotic gene and VRE reduction in germ free mice containing patient faeces, thus demonstrating the potential of bacteriocins as antibiotic alternatives ${ }^{42}$.

The gut microbiota also enables the gastrointestinal tract and the brain to communicate through the gut brain axis, which is described as a neuroendocrine signalling system that transmits information through endocrine signals, neurons and the immune system ${ }^{34}$. A recent microbiota-gut-brain-axis study demonstrated that nisin increased duodenal levels of the neurotransmitter serotonin (5hydroxytryptamine, 5-HT) and dopamine (DA) in a bacterial diarrhoea mouse model induced by pathogenic $E$. coli $\mathrm{O}_{1}$. In addition, nisin increased the bacterial diversity in the mouse cecum samples by increasing beneficial Lactobacillus, Bacteroides and Bifidobacterium species while inhibiting pathogenic $E$. coli and Enterococcus spp. Taken together the results show a positive correlation between nisin, the gut microbiota and stress reduction triggered by $E$. coli induced 
diarrhoea in mice suggesting that probiotics can both regulate the gut microbiota and affect the expression of neurotransmitters in the brain ${ }^{43}$.

\section{GENOME MINING STUDIES REVEAL THAT THE GUT MICROBIOTA IS A RICH SOURCE OF BACTERIOCIN GENES}

In silico genome mining techniques are routinely used to identify bacteriocin gene clusters in bacteria from numerous sources including the commensal mammalian microbiota. An in depth look at human commensal metagenomic sequences found that the number of putative bacteriocin genes varied according to body site with a higher proportion found in the mouth, airway and vagina and lowest in the gut ${ }^{44}$. However, analysis of genomes specifically from the human gut revealed that almost half, predominantly from LAB, encoded putative bacteriocins and are proposed to aid diversity through establishment of commensal relationships with the host and aid host defence by inhibiting pathogens ${ }^{45}$. In silico analysis of genomes from rumen bacteria found numerous novel sactipeptide and lanthipeptide bacteriocin gene clusters suggesting that the rumen is a rich source of novel antimicrobial peptides with potential as food preservatives and use in animal production ${ }^{46}$. A more recent metagenomic functional screening of the rumen metagenome identified 181 previously unidentified antimicrobial peptides, three of which (Lynronne-1, 2 and 3) were shown to have activity against methicillin resistant Staphylococcus aureus (MRSA) and other pathogens. Interestingly, MRSA did not produce resistant mutants when subcultured in sub MIC levels of these peptides over 25 days ${ }^{47}$.

Shotgun sequencing of the gut microbiome allows identification of microorganisms to species or strain level and even detects genes related to antibiotic resistance, vitamin production or short chain fatty acid production. However, advances in sequencing-based microbiome profiling methods such as metatranscriptomics, can go further to assess gene expression, thus providing an accurate method to determine which genes are expressed by the microbiome. This technique is capable of generating large scale profiles of complex microbiomes and is expected to improve our understanding of the role that bacteriocins play in gut ecology $y^{48}$ 


\section{BACTERIOCIN PRODUCING PROBIOTIC CULTURES AS ANTIMICROBIALS IN ANIMAL FEED}

Since the 1930s, antibiotics have been used in animal husbandry to treat infections, prevent disease and improve feed efficiency ${ }^{49}$. Antibiotic use in global food production is increasing worldwide to meet the growing demand for animal protein and now surpasses human consumption. Indeed, in some countries, it has been reported that $80 \%$ of antibiotics important for human medicine are consumed by healthy animals to promote growth ${ }^{50,51}$. Concerns about increases in drug resistance in animal pathogens and its potential transfer from livestock to humans, leading to untreatable infections, has led to the WHO introducing a Global Action Plan on Antimicrobial Resistance highlighting the need for a concerted international approach from consumers, environmentalists, agriculture, human and veterinary medicine to combat this growing crisis $^{51-53}$. In 2006, the European Union banned the use of animal growth promoters (AGP) in animal feed, creating a need for a new antimicrobial strategy. A pioneering study by Corr et al (2007) found that production of Abp118 by L. salivarius UCC118 protected mice in vivo from the food pathogen $L$. monocytogenes, thus confirming the antimicrobial potential of bacteriocin-producing probiotic cultures ${ }^{54}$. Since then there have been numerous studies, predominantly in vitro, providing evidence that bacteriocins are potential alternatives to antibiotics in animal production ${ }^{53}$. Recently, $\mathrm{Hu}$ et al (2018) showed that a faecal microbiota transplantation (FMT) from diarrhoea resistant to diarrhoea susceptible pigs protected against early weaning diarrhoea induced by stress, a huge problem in the swine industry. Further investigation revealed that the protective effect was attributable to the presence of Lactobacillus gasseri and Lactobacillus frumenti. More specifically, this effect was due to their ability to produce the circular bacteriocin, gassericin A, which binds to the pig's intestinal epithelial membrane, thus preventing diarrhoea onset and providing further evidence that probiotic cultures have potential as antibiotic alternatives for diarrhoea prevention in mammals ${ }^{55}$.

The ability of AGP to improve growth and body weight gain of animals is tentatively attributed to modulation of the gut microbiota as it plays an important role in obesity $^{33}$. Direct Fed Microbials (DFM) such as probiotic LAB are associated with weight gain in animals ${ }^{8}$ and tentative links are being established between feed efficiency in pigs and the intestinal microbiota ${ }^{56}$. This makes it tempting to suggest 
that bacteriocin-producing $L A B$ can be used to modulate the gut microbiota in a way that improves feed efficiency. Nisin has been proposed as a feed supplement for broiler chickens as preliminary experiments suggest that it improves body weight gain in a dose related manner, an effect that may be due to gut microbiota modulation ${ }^{57}$.

One of the challenges for bacteriocins in feed applications is the ability to pass through the gastrointestinal tract without digestion by proteolytic enzymes and this can be achieved through encapsulation, a protective technique that ensures successful delivery to the target site without loss of bioactivity where they can be released in a controlled fashion ${ }^{20}$. Both nisin $A$ and bactofencin $A$ were recently successfully encapsulated in mesoporous matrices with nisin $A$ being protected from degradation by pepsin and bactofencin A from trypsin ${ }^{58,59}$. Bioactive intact nisin and nisin fractions were detected in the faeces of mice pellets following feeding with nisin encapsulated in starch based matrices therefore achieving the aim of delivering intact nisin to the gut by oral means ${ }^{60}$. The amount of nisin detected in the faeces varied with starch matrix highlighting that optimum delivery requires examination of a range of substrates and conditions. These preliminary studies show that bacteriocins are effective in a gut environment.

\section{CONCLUSIONS}

Current research is strengthening the view of bacteriocins as being versatile antimicrobials with considerable potential for use as biopreservatives, antibiotic alternatives, health-promoting gut modulators and animal growth promoters. Excessive use of antibiotics, and especially of broad spectrum antibiotics, in medicine and food production has been recognised as a cause of microbiome disruption and select for accumulation and transfer of resistance genes within the microbial population of the human gut ${ }^{35}$. Overall, though bacteriocins are likely expressed at low levels in the gut, it is considered that their production by gut commensals enables a healthy and stable microbiome by preventing invasion by undesirable species $^{44}$ and the establishment of desirable microbes. 
The use of DFM as alternatives to AGP is a relatively new area of research that shows promise for bacteriocin-producing $L A B$ as initial studies show that bacteriocins are also effective in the animal gut. While obtaining approval from FDA and EFSA or other agencies to utilise bacteriocins within in feed additives for animal nutrition is a lengthy process ${ }^{61}$ their potential to play a role beyond that of biopreservative is notable, with a number of studies describing them as versatile health promoter molecules ${ }^{11,26}$.

The incorporation of bacteriocin-producing probiotics into foods and feeds and assuring their activity during processing and subsequent passage through the host's gastrointestinal tract is a challenge that is being addressed through the discovery and development of new bacteriocin producing strains and novel encapsulation techniques ${ }^{58-60,62}$. Commercial scale bacteriocin production is still hampered by high costs and low peptide yield but cost efficiency is being improved through optimisation of fermentation processes and bioengineering strains for maximum production of bacteriocins $^{63}$. It should also be noted that further studies are also required to establish dosage levels and to further improve effective delivery to target sites.

Overall, the expanding potential role of bacteriocins in food preservation, gut modulation, antimicrobial resistance reduction and animal feed suggest that if the hurdles described are overcome, there are considerable opportunities for widespread bacteriocin- based applications in the food and feed industries.

\section{ACKNOWLEDGEMENTS}

This work was funded by APC Microbiome Ireland, a research centre funded by Science Foundation Ireland (SFI), through the Irish Government's National Development Plan. The authors and their work were supported by SFI (grant no. 12/RC/2273) and São Paulo Research Foundation (FAPESP) grant 2015/24777-0, 2018/02519-7, 2018/04385-8 


\section{REFERENCES AND RECOMMENDED READING}

1 Ross, R. P., Morgan, S. \& Hill, C. Preservation and fermentation: past, present and future. Int J Food Microbiol 79, 3-16 (2002).

2 Macori, G. \& Cotter, P. D. Novel insights into the microbiology of fermented dairy foods. Curr Opin Biotechnol 49, 172-178, doi:10.1016/j.copbio.2017.09.002 (2018).

3 Galvez, A. L., R.L.; Pulido, R.P.; Burgos, M.J.G. In Food Biopreservation Vol. SpringerBriefs in Food, Health, and Nutrition. Springer, New York, NY 3-14 (Springer, New York, NY, 2014).

4 Cotter, P. D., Ross, R. P. \& Hill, C. Bacteriocins - a viable alternative to antibiotics? Nature reviews. Microbiology 11, 95-105, doi:10.1038/nrmicro2937 (2013).

* An insightful introduction to bacteriocins as potential antibiotic alternatives, as relevant today as when it was origonally published.

5 Silva, C. C. G., Silva, S. P. M. \& Ribeiro, S. C. Application of Bacteriocins and Protective Cultures in Dairy Food Preservation. Frontiers in microbiology 9, doi:Artn 59410.3389/Fmicb.2018.00594 (2018).

6 WHO Antibacterial Agents in Clinical Development. WHO. (2017).

7 Garcia-Gutierrez, E., Mayer, M. J., Cotter, P. D. \& Narbad, A. Gut microbiota as a source of novel antimicrobials. Gut microbes 10, 1-21, doi:10.1080/19490976.2018.1455790 (2019).

8 Vieco-Saiz, N., Belguesmia Y., Raspoet R., Auclair E., Gancel F., Kempf I. \& Drider D. Benefits and Inputs From Lactic Acid Bacteria and Their Bacteriocins as Alternatives to Antibiotic Growth Promoters During Food-Animal Production. Frontiers in microbiology 10, doi:Artn 57 10.3389/Fmicb.2019.00057 (2019).

9 Johnson, E. M., Jung Y.G., Jin Y.Y., Jayabalan R., Yang S.H. \& Suh J.W. Bacteriocins as food preservatives: Challenges and emerging horizons. Crit Rev Food Sci 58, 2743-2767, doi:10.1080/10408398.2017.1340870 (2018).

10 Snyder, A. B. \& Worobo, R. W. Chemical and genetic characterization of bacteriocins: antimicrobial peptides for food safety. J Sci Food Agr 94, 28-44, doi:Doi 10.1002/Jsfa.6293 (2014).

* Informative overview of the history, chemistry, genetic organisation and mode of action of bacteriocins and their potential applications in food

11 Chikindas, M. L., Weeks, R., Drider, D., Chistyakov, V. A. \& Dicks, L. M. Functions and emerging applications of bacteriocins. Curr Opin Biotechnol 49, 23-28, doi:10.1016/j.copbio.2017.07.011 (2018).

12 Field, D., Quigley L., O'Connor P.M., Rea M.C., Daly K., Cotter P.D., Hill C. and Ross R.P. Studies with bioengineered Nisin peptides highlight the broad-spectrum potency of Nisin V. Microb Biotechnol 3, 473-486, doi:DOI 10.1111/j.1751-7915.2010.00184.x (2010).

13 Field, D., Ross, R. P. \& Hill, C. Developing bacteriocins of lactic acid bacteria into next generation biopreservatives. Current Opinion in Food Science 20, 1-6, doi:10.1016/j.cofs.2018.02.004 (2018).

14 Martin-Visscher, L. A., Yoganathan, S., Sit, C. S., Lohans, C. T. \& Vederas, J. C. The activity of bacteriocins from Carnobacterium maltaromaticum UAL307 against gram-negative bacteria in combination with EDTA treatment. Fems Microbiol Lett 317, 152-159, doi:10.1111/j.1574-6968.2011.02223.x (2011).

15 Liu, X., Basu, U., Miller, P. \& McMullen, L. M. Stress Response and Adaptation of Listeria monocytogenes 08-5923 Exposed to a Sublethal Dose of Carnocyclin A. Appl Environ Microbiol 80, 3835-3841, doi:10.1128/AEM.00350-14 (2014).

16 Kone, A. P., Zea J.M.W., Gagne D., Cinq-Mars D., Guay F. \& Saucier L. Application of Carnobacterium maltaromaticum as a feed additive for weaned rabbits to improve meat 
microbial quality and safety. Meat science 135, 174-188, doi:10.1016/j.meatsci.2017.09.017 (2018).

17 Borrero, J., Kelly E., O'Connor P.M., Kelleher P., Scully C., Cotter P.D., Mahony J., \& van Sinderen D. Plantaricyclin A, a Novel Circular Bacteriocin Produced by Lactobacillus plantarum NI326: Purification, Characterization, and Heterologous Production. Appl Environ Microbiol 84, doi:10.1128/AEM.01801-17 (2018).

18 Orihuel, A. Bonacina J., Vildoza M.J., Bru E., Vignolo G., Saavedra L. \& Fadda S. Biocontrol of Listeria monocytogenes in a meat model using a combination of a bacteriocinogenic strain with curing additives. Food Res Int 107, 289-296, doi:10.1016/j.foodres.2018.02.043 (2018). Gomez-Sala, B., Herranz C., Diaz-Freitas B., Hernandez P. E., Sala A. \& Cintas L.M. Strategies to increase the hygienic and economic value of fresh fish: Biopreservation using lactic acid bacteria of marine origin. Int J Food Microbiol 223, 41-49, doi:10.1016/j.ijfoodmicro.2016.02.005 (2016).

20 Chandrakasan, G., Rodriguez-Hernandez, A. I., Del Rocio Lopez-Cuellar, M., Palma-Rodriguez, H. M. \& Chavarria-Hernandez, N. Bacteriocin encapsulation for food and pharmaceutical applications: advances in the past 20 years. Biotechnology letters 41, 453-469, doi:10.1007/s10529-018-02635-5 (2019).

21 Perales-Adan, J., Rubino S., Martinez-Bueno M., Valdivia E., Montalban-Lopez M., Cebrian R \& Maqueda M. LAB Bacteriocins Controlling the Food Isolated (Drug-Resistant) Staphylococci. Frontiers in microbiology 9, doi:Artn 1143 10.3389/Fmicb.2018.01143 (2018).

22 Bastos, M. D. D., Coelho, M. L. V. \& Santos, O. C. D. Resistance to bacteriocins produced by Gram-positive bacteria. Microbiol-Sgm 161, 683-700, doi:10.1099/mic.0.082289-0 (2015).

23 Dicks, L. M. T., Dreyer, L., Smith, C. \& van Staden, A. D. A Review: The Fate of Bacteriocins in the Human Gastro-Intestinal Tract: Do They Cross the Gut-Blood Barrier? Frontiers in microbiology 9, 2297, doi:10.3389/fmicb.2018.02297 (2018).

24 Geldart, K. \& Kaznessis, Y. N. Characterization of Class lla Bacteriocin Resistance in Enterococcus faecium. Antimicrob Agents Ch 61, doi:ARTN e02033-16 10.1128/AAC.0203316 (2017).

* This is an intersting study that the verifys the role of the Mannose PTS system in resistance to Class Ila bacteriocins.

25 Mathur, H., Field D., Rea M.C., Cotter P.D., Hill C. \& Ross R.P. Bacteriocin-Antimicrobial Synergy: A Medical and Food Perspective. Frontiers in microbiology 8, 1205, doi:10.3389/fmicb.2017.01205 (2017).

26 Martínez B., R. A., Suárez E. in New Weapons to Control Bacterial Growth. (ed Vinas M. (Eds.) Villa T.) 15-38 (Springer, Cham, 2016).

27 Draper, L. A., Cotter, P. D., Hill, C. \& Ross, R. P. Lantibiotic resistance. Microbiology and molecular biology reviews : MMBR 79, 171-191, doi:10.1128/MMBR.00051-14 (2015).

28 Algburi, A., Comito, N., Kashtanov, D., Dicks, L. M. T. \& Chikindas, M. L. Control of Biofilm Formation: Antibiotics and Beyond. Appl Environ Microb 83, doi:UNSP e02508-16 10.1128/AEM.02508-16 (2017).

29 Hols, P., Ledesma-Garcia, L., Gabant, P. \& Mignolet, J. Mobilization of Microbiota Commensals and Their Bacteriocins for Therapeutics. Trends in microbiology 27, 690-702, doi:10.1016/j.tim.2019.03.007 (2019).

30 Field, D., Blake T., Mathur H., O'Connor P.M., Cotter P.D., Ross R.P. \& Hill C. Bioengineering nisin to overcome the nisin resistance protein. Mol Microbiol, doi:10.1111/mmi.14183 (2018).

** This study describes a bioengineered nisin variant that is resistant to the nisin resistant protein and can be considered a significant advance in the fight against bacteriocin resistance 
31 Mills, S., Ross R.P. \& Hill C. A Multibacteriocin Cheese Starter System, Comprising Nisin and Lacticin 3147 in Lactococcus lactis, in Combination with Plantaricin from Lactobacillus plantarum. Appl Environ Microbiol 83, doi:10.1128/AEM.00799-17 (2017).

32 Campedelli, I., Mathur H., Salvetti E., Clarke S., Rea M.C., Torriani S., Ross R.P., Hill C. \& O'Toole P.W. Genus-Wide Assessment of Antibiotic Resistance in Lactobacillus spp. Appl Environ Microb 85, doi:UNSP e01738-18 10.1128/AEM.01738-18 (2019).

33 Dahiya, D. K., Renuka, Puniya M., Shandilya U.K., Dhewa T., Kumar N., Kumar S., Puniya A.K. \& Shukla P. Gut Microbiota Modulation and Its Relationship with Obesity Using Prebiotic Fibers and Probiotics: A Review. Frontiers in microbiology 8, 563, doi:10.3389/fmicb.2017.00563 (2017).

* Excellent review describing the role of the gut microbiota in obesity and how probiotics/prebiotcs may be used as therapeutics to attain a more favorable microbial balance

34 Westfall, S., Lomis N., Kahouli I., Dia S.Y., Singh S.P. \& Prakash S. Microbiome, probiotics and neurodegenerative diseases: deciphering the gut brain axis. Cell Mol Life Sci 74, 3769-3787, doi:10.1007/s00018-017-2550-9 (2017).

* This review describes the link between the gut microbiota and the gut brain axis and its role in neurodegerative diseases

35 Francino, M. P. Antibiotics and the Human Gut Microbiome: Dysbioses and Accumulation of Resistances. Frontiers in microbiology 6, 1543, doi:10.3389/fmicb.2015.01543 (2015).

* Excellent review describing the relationship between antibiotcs and the gut microbiome particularly in relation to resistance genes

36 Bauerl, C., Umu, O. C. O., Hernandez, P. E., Diep, D. B. \& Perez-Martinez, G. A Method to Assess Bacteriocin Effects on the Gut Microbiota of Mice. Journal of visualized experiments : JoVE, doi:10.3791/56053 (2017).

* This study describes a method to compare bacteriocin producing strains with their non producing isogenic counterparts in an in vivo model, allowing comparisons of gut microbiota modifications due to these strains

37 Dobson, A., Cotter, P. D., Ross, R. P. \& Hill, C. Bacteriocin production: a probiotic trait? Appl Environ Microbiol 78, 1-6, doi:10.1128/AEM.05576-11 (2012).

38 Guinane, C. M., Lawton E.M., O'Connor P.M., O'Sullivan O., Hill C., Ross R.P. \& Cotter P.D. The bacteriocin bactofencin A subtly modulates gut microbial populations. Anaerobe 40, 41-49, doi:10.1016/j.anaerobe.2016.05.001 (2016).

39 Murphy, E. F., Cotter P.D., Hogan A., O'Sullivan O., Joyce A., Fouhy F., Clarke S.F., Marques T.M., O'Toole P.W., Stanton C., Quigley E.M., Daly C., Ross R.P., O'Doherty R.M. \& Shanahan F. Divergent metabolic outcomes arising from targeted manipulation of the gut microbiota in diet-induced obesity. Gut 62, 220-226, doi:10.1136/gutjnl-2011-300705 (2013).

40 Hegarty, J. W., Guinane, C. M., Ross, R. P., Hill, C. \& Cotter, P. D. Bacteriocin production: a relatively unharnessed probiotic trait? F1000Research 5, 2587, doi:10.12688/f1000research.9615.1 (2016).

41 Umu, O. C., Bauerl C., Oostindjer M., Pope P.B., Hernandez P.E., Perez-Martinez G. \& Diep D.B. The Potential of Class II Bacteriocins to Modify Gut Microbiota to Improve Host Health. PLoS One 11, e0164036, doi:10.1371/journal.pone.0164036 (2016).

$42 \mathrm{Kim}, \mathrm{S}$. G. et al. Microbiota-derived lantibiotic restores resistance against vancomycinresistant Enterococcus. Nature 572, 665-669, doi:10.1038/s41586-019-1501-z (2019).

** This is a significant study that shows that lantibiotic gene expression in the gut protects against VREf, a significant pathogen of increasing concern in hopital aquired infections. 

microbiome-brain-gut axis neurochemicals by Escherichia coli-induced diarrhea in mice. Microbial pathogenesis 119, 65-71, doi:10.1016/j.micpath.2018.04.005 (2018). Zheng, J., Ganzle, M. G., Lin, X. B., Ruan, L. \& Sun, M. Diversity and dynamics of bacteriocins from human microbiome. Environmental microbiology 17, 2133-2143, doi:10.1111/14622920.12662 (2015).

45 Drissi, F., Buffet, S., Raoult, D. \& Merhej, V. Common occurrence of antibacterial agents in human intestinal microbiota. Frontiers in microbiology 6, doi:Artn 441 10.3389/Fmicb.2015.00441 (2015).

46 Azevedo, A. C., Bento, C. B. P., Ruiz, J. C., Queiroz, M. V. \& Mantovani, H. C. Distribution and Genetic Diversity of Bacteriocin Gene Clusters in Rumen Microbial Genomes. Appl Environ Microb 81, 7290-7304, doi:10.1128/Aem.01223-15 (2015).

47 Oyama, L. B. et al. The rumen microbiome: an underexplored resource for novel antimicrobial discovery. NPJ Biofilms Microbiomes 3, 33, doi:10.1038/s41522-017-0042-1 (2017).

48 Cottier, F., Srinivasan K.G., Yurieva M., Liao W., Poidinger M., Zolezzi F. \& Pavelka N. Advantages of meta-total RNA sequencing (MeTRS) over shotgun metagenomics and amplicon-based sequencing in the profiling of complex microbial communities. Npj Biofilms Microbi 4, doi:Unsp 2 10.1038/S41522-017-0046-X (2018).

** This study describes meta-total RNA sequencing (MeTRS) a new technique, more sensitive and reproducible than shotgun metagenomics and amplicon based sequencing with potential to profile complex microbiomes

49 Kirchhelle, C. Pharming animals: a global history of antibiotics in food production (19352017). Palgrave Communications 4, 96, doi:10.1057/s41599-018-0152-2 (2018).

** This review is a comprehensive overview of the history of agriultural antibiotic use from their initial success in the areas of food preservation, disease prevention and feed conversion to concerns about drug residues and antimicrobial resistance and the need for a concerted international effort to combat these issues.

50 Mendelson, M. \& Matsoso, M. P. The World Health Organization Global Action Plan for antimicrobial resistance. South African medical journal = Suid-Afrikaanse tydskrif vir geneeskunde 105, 325, doi:10.7196/samj.9644 (2015).

51 Van Boeckel, T. P. et al. Reducing antimicrobial use in food animals Consider user fees and regulatory caps on veterinary use. Science 357, 1350-1352, doi:10.1126/science.aao1495 (2017).

52 WHO. Global action plan on antimicrobial resistance. (2015).

53 Ben Lagha, A., Haas, B., Gottschalk, M. \& Grenier, D. Antimicrobial potential of bacteriocins in poultry and swine production. Vet Res 48, doi:ARTN 22 10.1186/s13567-017-0425-6 (2017).

* This review describes a number of studies providing evidence that bacteriocins are potential antibiotc alternatves in animal production, praticularly, in the poultry and swine industry.

54 Corr, S. C., Li Y., Riedel C.U., O'Toole P.W., Hill C. \& Gahan C.G.M. Bacteriocin production as a mechanism for the antfinfective activity of Lactobacillus salivarius UCC118. Proc. Natl. Acad. Sci. U. S. A. 104, 7617-7621, doi:10.1073/pnas.0700440104 (2007).

$55 \quad H u$, J., Ma L.B., Nie Y.F., Chen J.W., Zheng W.Y., Wang X.K., Xie C.L., Zheng Z.L., Wang Z.C., Yang T., Shi M., Chen L.L., Hou Q.L., Niu Y.R., Xu X.F., Zhu Y.H., Zhang Y., Wei H. \& Yan X.H. A Microbiota-Derived Bacteriocin Targets the Host to Confer Diarrhea Resistance in EarlyWeaned Piglets. Cell host \& microbe 24, 817-+, doi:10.1016/j.chom.2018.11.006 (2018). 
** This is a pioneering study describing how a faecal microbiota transplant contaning bacteriocin producing strains protected vunerbale piglets from stress induced diarrhea.

56 McCormack, U. M., Curiao T., Buzoianu S.G., Prieto M.L., Ryan T., Varley P., Crispie F., Magowan E., Metzler-Zebeli B.U., Berry D., O'Sullivan O., Cotter P.D., Gardiner G.E. \& Lawlor P.G. Exploring a Possible Link between the Intestinal Microbiota and Feed Efficiency in Pigs. Appl Environ Microb 83, doi:UNSP e00380-17 10.1128/AEM.00380-17 (2017).

57 Jozefiak, D., Kieronczyk B., Juskiewicz J., Zdunczyk Z., Rawski M., Dlugosz J., Sip A. \& Hojberg O. Dietary Nisin Modulates the Gastrointestinal Microbial Ecology and Enhances Growth Performance of the Broiler Chickens. PLOS One 8, doi:ARTN e8534710.1371/journal.pone.0085347 (2013).

58 Flynn, J., Mallen, S., Durack, E., O'Connor, P. M. \& Hudson, S. P. Mesoporous matrices for the delivery of the broad spectrum bacteriocin, nisin A. Journal of colloid and interface science 537, 396-406, doi:10.1016/j.jcis.2018.11.037 (2019).

59 Durack, E. Mallen S., O'Connor P.M., Rea M.C., Ross R.P., Hill C. \& Hudson S. Protecting bactofencin $A$ to enable its antimicrobial activity using mesoporous matrices. International journal of pharmaceutics 558, 9-17, doi:10.1016/j.ijpharm.2018.12.035 (2019).

60 Gough, R., Cabrera Rubio R., O'Connor P.M., Crispie F., Brodkorb A., Miao S., Hill C., Ross R.P., Cotter P.D., Nilaweera K.N. \& Rea M.C. Oral Delivery of Nisin in Resistant Starch Based Matrices Alters the Gut Microbiota in Mice. Frontiers in microbiology 9, 1186, doi:10.3389/fmicb.2018.01186 (2018).

61 EFSA Panel on Additives, Guidance on the assessment of the safety of feed additives for the consumer. EFSA Journal 15, e05022, doi:10.2903/j.efsa.2017.5022 (2017).

62 Chawda, P. J., Shi, J., Xue, S. \& Young Quek, S. Co-encapsulation of bioactives for food applications. Food Quality and Safety 1, 302-309, doi:10.1093/fqsafe/fyx028 (2017).

63 Ozel, B., Simsek, O., Akcelik, M. \& Saris, P. E. J. Innovative approaches to nisin production. Applied microbiology and biotechnology 102, 6299-6307, doi:10.1007/s00253-018-9098-y (2018). 


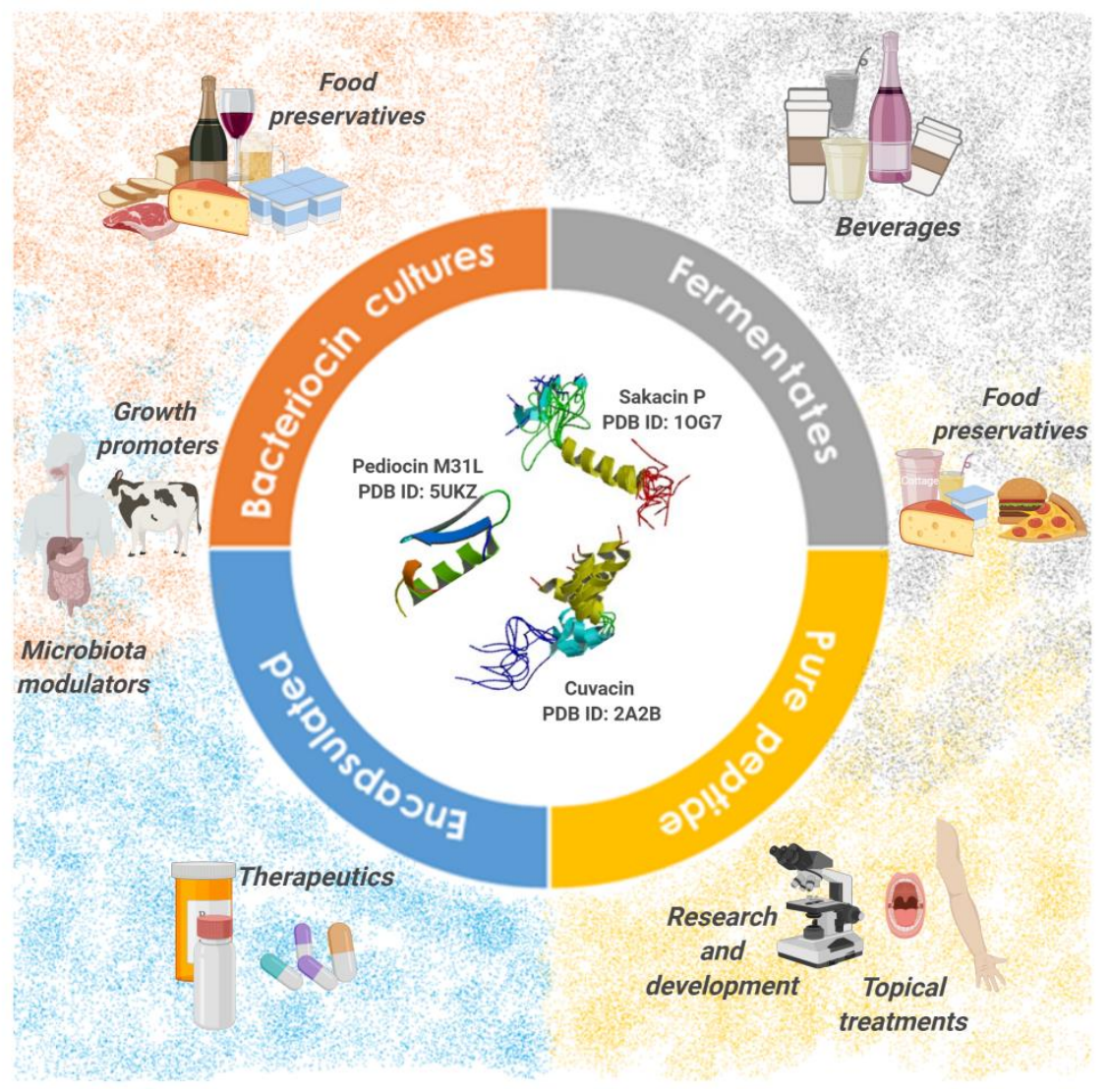

Figure 1. Potential applications of i) bacteriocin producing cultures, ii) bacteriocin containing fermentates, iii) purified bacteriocins and iv) encapsulated bacteriocins as food preservatives, gut modulators, feed additives and therapeutics. Created with BioRender.com. PDB ID 2A2B (10.2210/pdb2a2b/pdlb), PDB ID $10 \mathrm{OG}$ (10.2210/pdb1OG7/pdb), PDB ID 5UKZ (10.2210/pdb5UKZ/pdb). 


\section{HIGHLIGHTS}

- Novel bacteriocins with potential as food preservatives are continuously being discovered

- A hurdle approach is improving the efficacy of bacteriocins in foods and reducing of antimicrobial resistance

- Bioengineering is being used to design bacteriocins with improved antimicrobial resistance

- Bacteriocin producing strains may promote host health through modulation of the gut microbiome

- DFM show potential as alternatives to antibiotic growth promoters in animal feed 